This item was submitted to Loughborough's Institutional Repository (https://dspace.lboro.ac.uk/) by the author and is made available under the following Creative Commons Licence conditions.

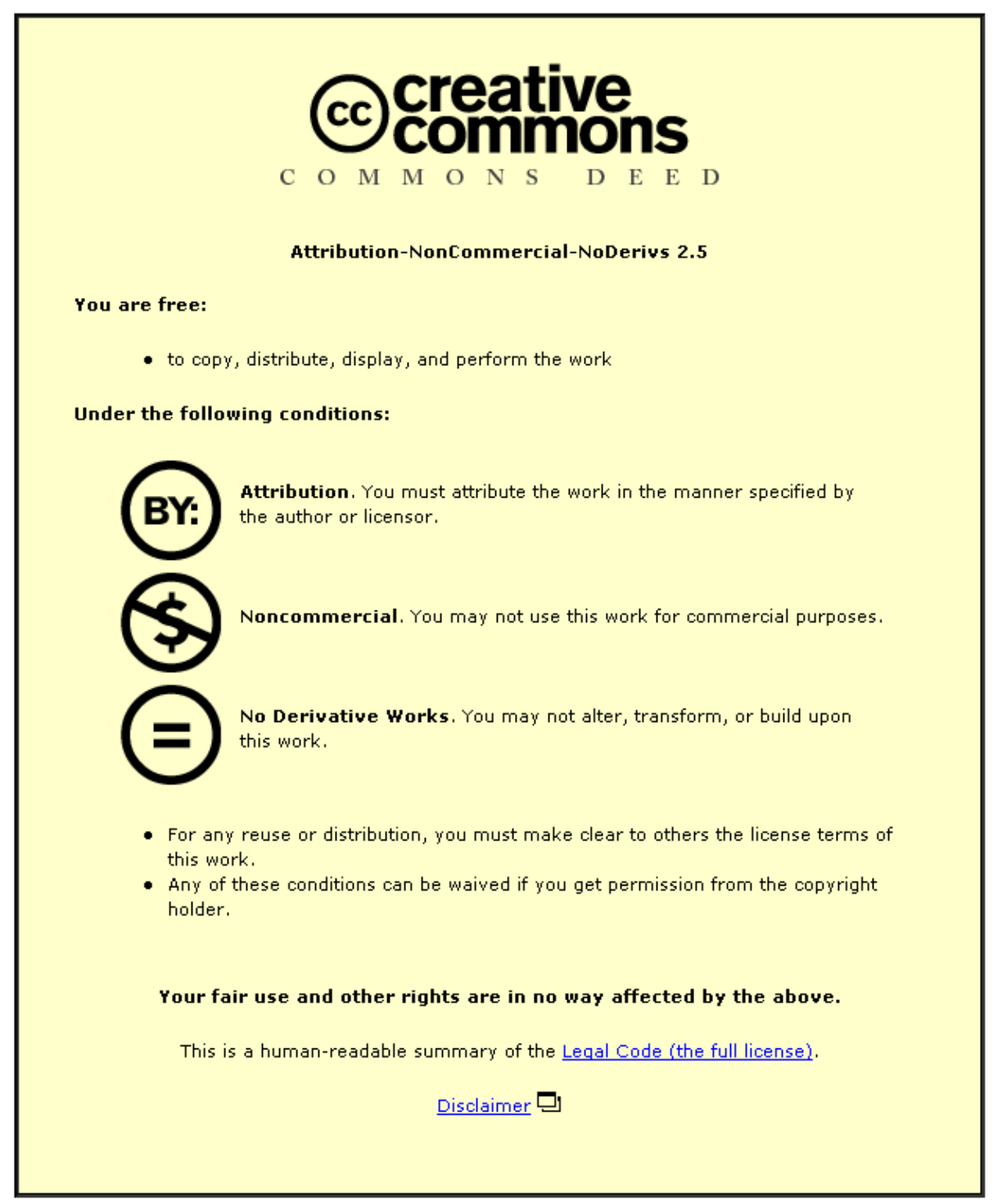

For the full text of this licence, please go to: http://creativecommons.org/licenses/by-nc-nd/2.5/ 


\title{
Under Bump Metallisation of Fine Pitch Flip-chip Using Electroless Nickel Deposition
}

\author{
C. Liu, D.A. Hutt, D.C. Whalley, P.P. Conway \\ Interconnection Group, Wolfson School of Mechanical and Manufacturing Engineering, \\ Loughborough University, Loughborough, LE1 1 3TU, UK \\ S.H. Mannan \\ Department of Mechanical Engineering \\ King's College London, Strand, London WC2R 2LS, UK.
}

\begin{abstract}
For solder based flip-chip assembly, the deposition of an under bump metallisation (UBM) layer onto the surface of the Al bondpads of the die is the first step in the wafer bumping process. The UBM is necessary, as the fragile $\mathrm{Al}$ pad has a tenacious oxide layer that cannot be soldered without the use of strong fluxes and a barrier layer is required to prevent dissolution of the bondpad into the solder during reflow. The requirements of the UBM are therefore to provide a solder wettable surface and to protect the underlying $\mathrm{Al}$ bondpad during and after assembly. In addition, the UBM deposition process itself must remove any oxide layers on the bondpads to ensure a low resistance interface between the pad and the UBM. This paper reports an investigation of the electroless nickel deposition process for the under bump metallisation of wafers that are subsequently to be bumped using solder paste printing. In particular this work has extended the process from previous trials on $225 \mu \mathrm{m}$ pitch devices to wafers including die with sub $100 \mu \mathrm{m}$ pitch bondpads. As part of this work, the effect of the various pre-treatment etching processes and zincate activation on the quality of the final electroless nickel bump has been investigated. The use of SEM examination of samples at each stage of the bumping process has been used to aid a detailed understanding of the activation mechanisms and to determine their effects on the electroless nickel bump morphology. In addition shear testing of bumps has been used to determine the best pre-treatment regime to ensure good adhesion of the electroless nickel to the bondpad. Finally, electrical resistance measurements of bumped die have been used to confirm that the pre-treatment procedures are producing a low resistance interface between the $\mathrm{Al}$ and electroless nickel.
\end{abstract}

\section{Introduction}

Flip chip technology has seen increasing demand due to its many advantages including miniaturization and high electrical performance. As a result, a number of methods and various hybrid techniques have been explored in order to achieve high volume production of flip-chip devices at low cost. Presently, solder based interconnection of die to substrates offers a cost effective solution which fits more closely within the current PCB assembly infra-structure. This process involves the deposition of solder material onto the bondpads of the die to form a bump which is subsequently used to form an interconnection with a PCB or other such substrate.

A process that has received considerable interest as a low cost wafer bumping technique is electroless nickel plating, followed by solder paste printing. The electroless $\mathrm{Ni}$ plating process has been investigated by several groups [1-8] and forms an under bump metallisation layer on the Al bondpad by means of the deposition of a thin (typically $5-30 \mu \mathrm{m}$ thick) film of NiP alloy. The electroless nickel deposition technique is a maskless process for which the existing wafer passivation acts as a mask, allowing the deposition of electroless nickel only onto the $\mathrm{Al}$ bondpads. However, the Al surface is not directly active to electroless nickel deposition and must be activated through a number of pre-treatment steps including typically a zincate treatment.

This paper reports an investigation of the formation of this type of electroless $\mathrm{Ni}$ under bump on the bondpads of wafers including die with sub $100 \mu \mathrm{m}$ pitch bondpads. The effect of the various pre-treatment etching processes and zincate activation on the quality of the final electroless nickel bump were studied by using SEM examination to aid a detailed understanding of the activation mechanisms and to determine their effects on the electroless Ni bump morphology. Bump shear tests were performed to determine the best pre-treatment regime to ensure good adhesion of the electroless nickel to the bondpad and electrical resistance measurements of bumped die were used to ensure that the pre-treatment procedures produce a low resistance interface between the $\mathrm{Al}$ and electroless $\mathrm{Ni}$. Finally, stencil printing was used to produce solder bumps on the UBM thereby forming solder balls which can be readily reflowed onto the $\mathrm{PCB}$ during the assembly process.

\section{Experimental Procedure}

\section{Wafers used for bumping trials}

Two types of wafers were used in this work. Wafer type A was manufactured by a commercial organisation and consisted of $6 \times 6 \mathrm{~mm}$ die with daisy chain test structures. The bondpads, which were $\mathrm{Al}-\mathrm{Cu}(1 \%)$ alloy, were arranged around the periphery of the die at pitches of $225 \mu \mathrm{m}$ and $300 \mu \mathrm{m}$. The pads were $3 \mu \mathrm{m}$ in thickness, octagonal in shape with a width across the flats of $90 \mu \mathrm{m}$. The opening in the passivation over the pads had a diameter of $75 \mu \mathrm{m}$. 
Wafer type B was designed as a test vehicle to determine the bondpad pitch limitations of the electroless nickel and solder paste printing processes, and was manufactured by a University facility. This wafer type included a number of $3 \times 3 \mathrm{~mm}$ die with pure $\mathrm{Al}$ bondpads that were $1 \mu \mathrm{m}$ thick. The bondpads were arranged to form daisy-chain structures in both peripheral and full array layouts at pitches of $150 \mu \mathrm{m}, 125 \mu \mathrm{m}, 100 \mu \mathrm{m}$, and $90 \mu \mathrm{m}$. The bondpads were octagonal in shape with a $60 \mu \mathrm{m}$ diameter opening in the passivation over the pads for those die with pitches of $150 \mu \mathrm{m}, 125 \mu \mathrm{m}, 100 \mu \mathrm{m}$, and a diameter of $50 \mu \mathrm{m}$ for pads at $90 \mu \mathrm{m}$ pitch.

\section{Electroless nickel bumping}

For the electroless nickel deposition process the samples were treated in a series of chemical baths following the process route shown in Figure 1.

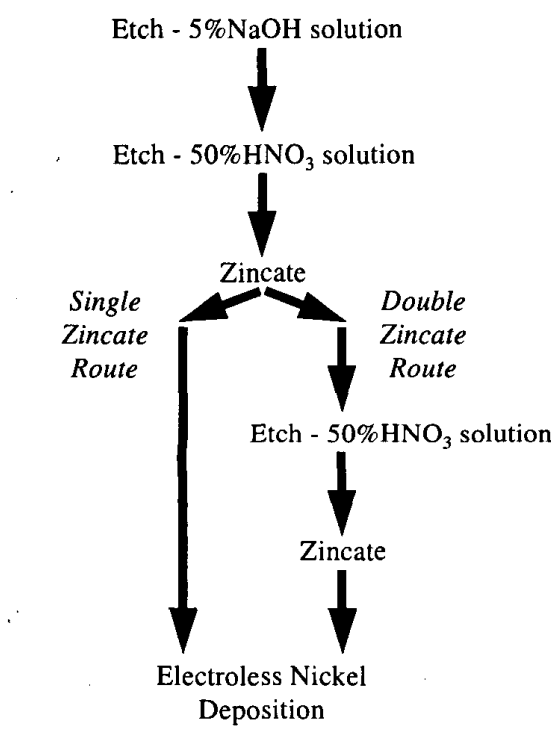

Figure 1: Process route for electroless Ni bumping of $\mathrm{Al}$ bondpads.

As the $\mathrm{Al}$ surface is not directly active to electroless nickel bumping, a number of alkaline and acid etches were applied, followed by a zincate treatment using a commercially available solution. This process route only activated the exposed $\mathrm{Al}$ surface, leaving the wafer passivation inactive and resulting in the selective deposition of electroless nickel onto the bondpads. The time used for the pre-treatment processes (i.e. etch and zincate) is important and will be discussed further in the following sections. Depending on the composition and thickness of the Al bondpads, the time of immersion of the samples in the pre-treatment chemical baths ranged from 10 to 60 s.
The electroless Ni was deposited from a proprietary, acid based, hypophosphite bath, which produced a NiP deposit containing $4-5 \mathrm{wt} \% \mathrm{P}$. The plating process is isotropic, resulting in both the outward and upward growth of the deposit producing a "mushroom" shaped crosssection. The deposition rate of $18-20 \mu \mathrm{m} \cdot \mathrm{hr}^{-1}$ enabled close control of the NiP thickness to be obtained through monitoring of the plating time. In the present work, a typical NiP coating thickness of $5 \mu \mathrm{m}$ was used, which has proved satisfactory for the production of a reliable UBM interlayer for further soldering processes. However, $15 \mu \mathrm{m}$ $\mathrm{Ni}$ coatings were also prepared on some die in order to facilitate evaluation of their interfacial adhesion by shear testing.

\section{Stencil solder paste printing}

Stencil printing of solder paste was used to solder bump wafers that had been electroless nickel plated to a thickness of $5 \mu \mathrm{m}$. A DEK Printing Machines Ltd. DEK265 printing machine was used to print a fine particle size solder paste onto the wafers which was then reflowed to form solder balls on the pads. It was found that the activity of the paste used in these trials was sufficient to enable reliable reflow of the solder onto the electroless nickel without a preserving immersion gold layer. Solder printing and reflow was only carried out with wafer A, which has pad pitches of $225 \mu \mathrm{m}$ and $300 \mu \mathrm{m}$. Further trials on the fine pitch structures of wafer $B$ are currently underway.

\section{Shear testing for interfacial adhesion evaluation}

A Dage Series 4000 Multi-purpose Bond Tester with BS250 Ball Shear cartridge was employed to carry out shear tests on bumped wafers. Shear tests were conducted at a pre-set height above the substrate and the effect of this shear height (distance between the blade and the die surface) on the results was investigated. For wafers bumped only with electroless nickel, thick $(\sim 15 \mu \mathrm{m})$ deposits had to be used to enable the shear tool to gain purchase on the side of the bump. In all tests, a shear speed of $150 \mu \mathrm{m} / \mathrm{s}$ was used.

\section{Electrical resistance measurements}

Four point resistance measurements were carried out using a wafer prober and a micro-ohmeter in order to evaluate the effects of the electroless $\mathrm{Ni}$ bumping process on the conductivity of the bondpads on the die. Measurements were conducted before and after electroless $\mathrm{Ni}$ bumping. For wafers of type A the resistances between pads of both $225 \mu \mathrm{m}$ and $300 \mu \mathrm{m}$ pitches were measured, while for wafer B only the resistance between pads at $150 \mu \mathrm{m}$ pitches with peripheral layout was measured. Each resistance presented here is a mean value of at least six measurements.

\section{SEM observation of the morphology of Ni bumps}

An SEM was used to examine the surface morphology, of the Ni plating. The elemental composition of the sample surface was also analysed using $\mathrm{X}$-ray emission spectroscopy. In this work, the surface of the 
bondpads before and after each step of the process route, i.e. etching, zincate, and $\mathrm{Ni}$ plating processes was examined.

\section{Results and Discussion}

\section{Influence of bondpad composition and morphology on electroless Ni bumping}

The surface of bare bondpads before bumping is shown in Figure 2. The morphologies of the two wafer types are different, indicating that the processes adopted by suppliers are different in terms of the technologies used and processing parameters. The bondpads on wafer $A$ were very smooth and uniform, with some evidence of grain boundaries. The surface of the bondpads on wafer B had a coarser texture structure, with a number of pores or pinholes. The difference between the two structures may be a result of different processing or different alloy composition: wafer A was composed of $\mathrm{Al}-\mathrm{Cu}(1 \%)$ alloy, while wafer $\mathrm{B}$ was pure $\mathrm{Al}$ metal.
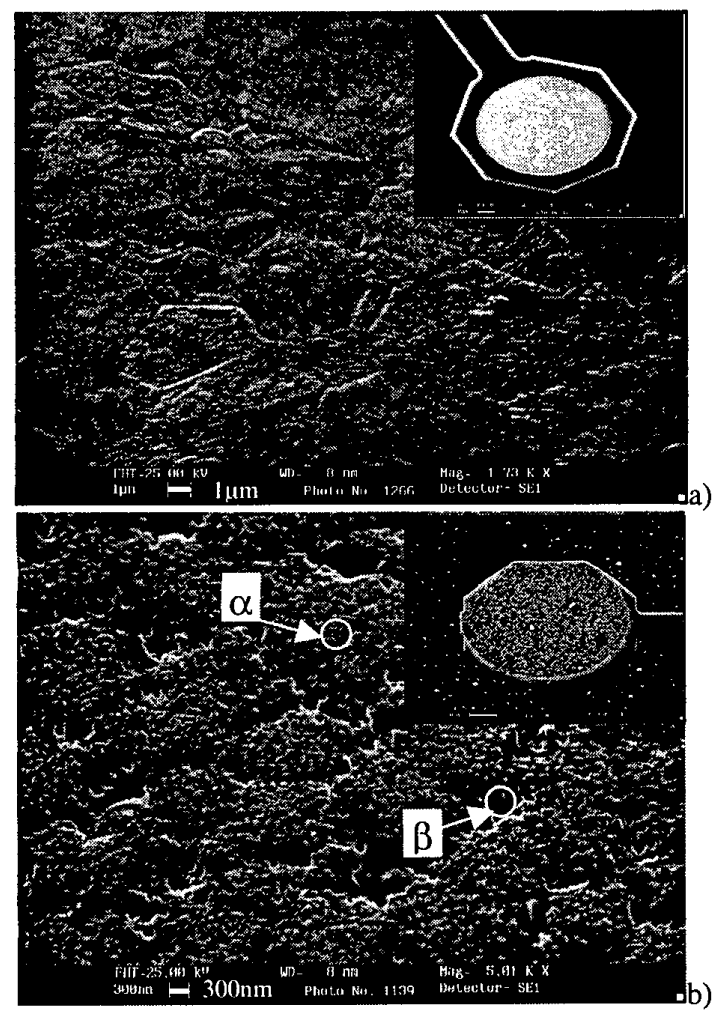

Figure 2. SEM micrographs of bond pads from a) wafer A, and b) wafer $B$.

Table 1: X-ray analysis of element composition (Wt\%) on the areas $\alpha$ and $\beta$ marked in figure $2 b$

\begin{tabular}{|l|l|l|}
\hline & $\alpha$ & $\beta$ \\
\hline $\mathrm{Al}$ & 45.15 & 34.33 \\
\hline $\mathrm{Si}$ & 54.86 & 65.67 \\
\hline
\end{tabular}

The pure Al pads on wafer B were approximately $1 \mu \mathrm{m}$ thick. It is critical that local defects such as pinholes do not reduce the thickness of this Al layer. X-ray analysis carried out in the SEM on the areas indicated in Figure $2 b$ showed significant differences in the amount of $\mathrm{Al}$ present in these regions (Table 1 ). Area $\beta$ (porous area) showed a higher $\mathrm{Si}$ signal from the substrate underneath the $\mathrm{Al}$ layer.

The initial structure and composition of the bondpads is expected to affect the etching and zincate processes with respect to the final surface properties and morphology. Figure 3 shows SEM micrographs obtained from $\mathrm{Al}-\mathrm{Cu}$ alloy and pure $\mathrm{Al}$ bondpads after single and double zincate treatments. As reported by $\mathrm{Lu}$ et al [6], the zincate film is finer-grained, thinner and more uniform on $\mathrm{Al}-\mathrm{Cu}-\mathrm{Si}$ alloys than on pure Al. Similarly, in the present work, the zincate process was found to produce a more uniform, and finer-grained film on the $\mathrm{Al}-\mathrm{Cu}$ alloy pads of wafer $\mathrm{A}$, compared to that on the pure $\mathrm{Al}$ bondpads of wafer $\mathrm{B}$. As expected, the film produced by the double zincate treatment of the $\mathrm{Al}-\mathrm{Cu}$ pads was thinner, finer and denser than that formed by the single zincate process. However, this was not the case for the pure Al bondpads of wafer B and this will be discussed further below.

The zincate treatment has been investigated by a number of research groups [9-14]. Generally, the zincate treatments employed have been alkaline solutions, which can remove the $\mathrm{Al}$ oxide so that an active fresh surface of $\mathrm{Al}$ metal or alloy will be exposed. $\mathrm{Zn}$ atoms are then substituted for $\mathrm{Al}$ atoms at the surface. Insufficient zincation such as may occur due to non-uniform decomposition of the oxide layer or locally different dissolution rates, can cause segregated $\mathrm{Zn}$ substitution and non-uniform Ni plating[12]. The factors which can affect the uniformity and coverage of zincate films are complicated due to the physical, metallurgical and electrochemical characteristics of the zincate processes.

In this study, the Al-Cu alloy bondpads on wafer A appear to be smooth on a microscopic scale, with a number of grains in the range of $5-10 \mu \mathrm{m}$ (Figure $2 \mathrm{a}$ ). As can be seen in Figure $3 a$, the precipitation of $\mathrm{Zn}$ clusters during the zincate treatment occurred uniformly over the surface, but larger $\mathrm{Zn}$ clusters segregated on the lines of the grain boundaries. These boundaries possess higher free energies than the body of the grains and are therefore more easily activated in the zincate solution, leading to the greater nucleation of $\mathrm{Zn}$ particles. Closer examination of the bondpad surface revealed the formation of pits between the $\mathrm{Zn}$ particles, which were presumably formed by the dissolution of $\mathrm{Al}$ leading to the reduction of $\mathrm{Zn}$ ions in solution at the grain boundaries. The double zincate treatment produced a finer and more uniform zincate deposit with less dependence on the grain boundary structure. After etching of the first zincate layer on wafer $\mathrm{A}$ in nitric acid, X-ray analysis showed no evidence of zinc on the surface, indicating that the second smoother zincate layer must have nucleated from the $\mathrm{Al}$ surface, not from residual $\mathrm{Zn}$ particles. This implies that the surface after the nitric acid etch had a more uniform distribution of nucleation sites, probably related to the etch pits observed 
in the $\mathrm{Al}$ following the initial zincate treatment. It is unclear at this stage whether the additional alloying element $(\mathrm{Cu})$ improves the uniformity of the $\mathrm{Zn}$ film by generating more nucleation sites for the zincate.

The different compositions of the $\mathrm{Al}$ bondpad can lead to different dissolution rates in the $\mathrm{NaOH}$ and zincate solutions. This is particularly important for the pure $\mathrm{Al}$ bondpads on wafer $B$ which are as thin as $1 \mu \mathrm{m}$ and could be easily damaged by this process. As reported by Lu [6], the dissolution rate of $\mathrm{Al}$ is approximately $0.02 \mu \mathrm{m}$ per second, which is slower than Al-Cu-Si. Moreover, the dissolution rate may be even higher at the grain boundaries, producing a more uneven surface. In this work, the dissolution rate of $\mathrm{Al}-\mathrm{Cu}$ was found to be less than that of pure $\mathrm{Al}$.

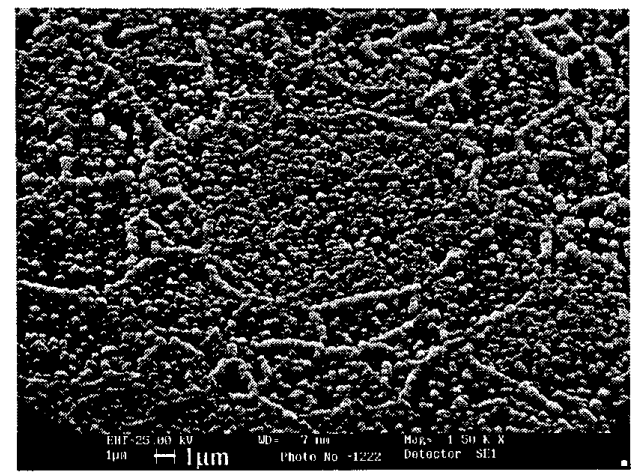

a) Wafer $A 20$ s single zincate

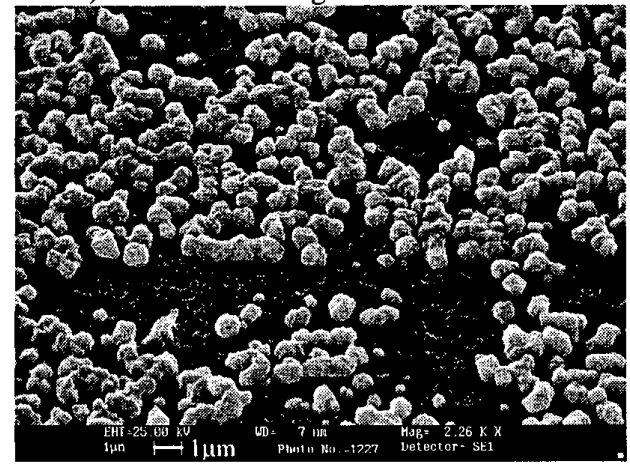

c) Wafer B 10 s single zincate

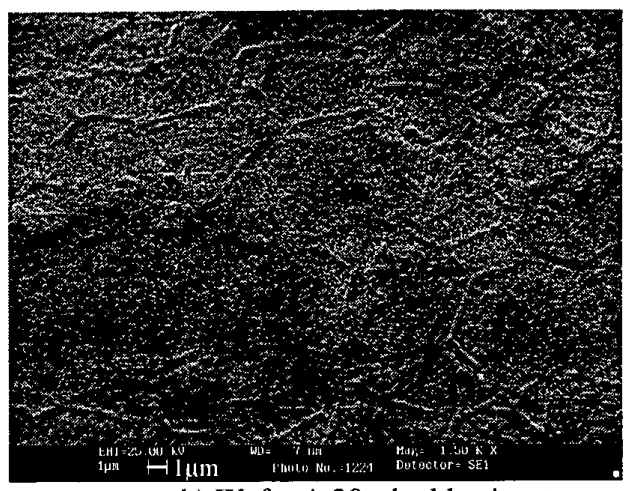

b) Wafer A 20s double zincate

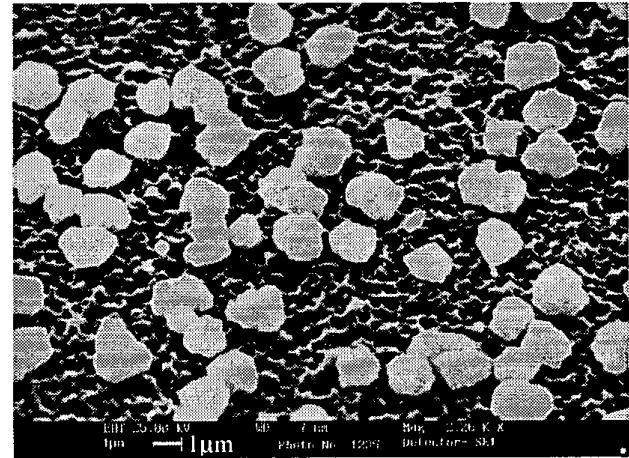

d) Wafer B 10s double zincate

Figure 3. Zincate film characteristic after single and double zincate treatment

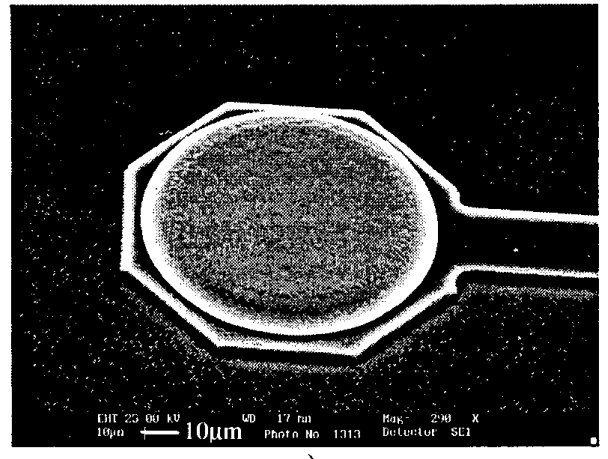

a)

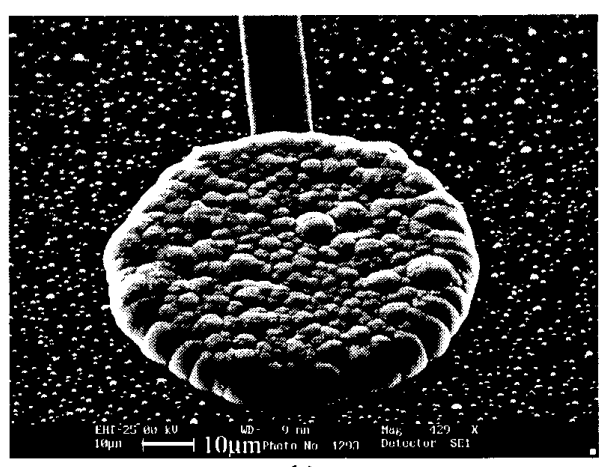

b)

Figure 4. SEM micrographs of electroless Ni bumps a) $225 \mu \mathrm{m}$ pitch on wafer A, and b) $150 \mu \mathrm{m}$ pitch on wafer B 
It appears that the coarse surface texture of the $\mathrm{Al}$ pads on wafer $B$ is detrimental to the uniformity and coverage of the $\mathrm{Zn}$ layer. Bigger islands of $\mathrm{Zn}$ were observed on these pads after zincate treatment (Figures 3 (c) \& (d)). The reasons why the second zincate did not produce a more uniform and better coverage $\mathrm{Zn}$ layer (as observed for wafer A) are unclear, but may be due to large residual $\mathrm{Zn}$ clusters formed from the first zincate, which were not entirely removed during the nitric acid etching process before the second zincate treatment. These residual $\mathrm{Zn}$ clusters could continue to grow during the second zincate treatment, resulting in the even larger $\mathrm{Zn}$ clusters observed (Figure 3 (d)). Alternatively, the localised thinning of the pure Al pads due to the first zincate step may cause the underlying $\mathrm{Si}$ to be exposed, thereby significantly reducing the number of nucleation sites. Further studies are planned to investigate this.

As expected, the nature of the zincate treatment on the bondpads can significantly alter the appearance and morphology of the subsequent $\mathrm{Ni}$ plating. Figure 4 shows examples of electroless $\mathrm{Ni}$ bumped bondpads from wafers

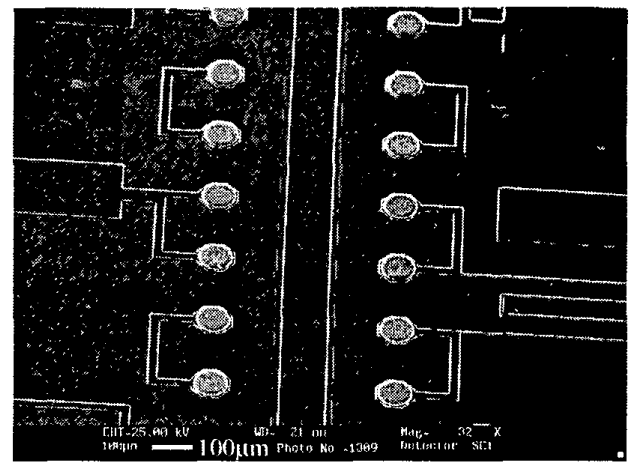

a)
$\mathrm{A}$ and $\mathrm{B}$. In this case the Ni bumps were produced by a 20 s double zincate for wafer $A$ and a 10 s single zincate for wafer $\mathrm{B}$. The Ni bump on wafer A is smoother than that on wafer $\mathrm{B}$. The rough finish of the Ni bump on wafer B may be attributed to the big $\mathrm{Zn}$ clusters produced by the zincate treatment. A mushroom-like bump shape was produced on both wafer A and wafer B, but for wafer B the overall shape appears to be the result of the merging of individual bumps nucleated from each of the $\mathrm{Zn}$ clusters.

\section{Shear strength evaluation of the electroless Ni bumps}

As shown in the overall SEM images of figure 5, the UBM Ni bumps were generally uniform in size and shape. Although the surface morphology of the $\mathrm{Ni}$ on wafer $\mathrm{B}$ was not as smooth as on wafer A, it is still acceptable for further solder deposition. However, it is important to keep the surface of the passivation free of electroless nickel deposits, a situation that is particularly important for fine pitch devices [8].

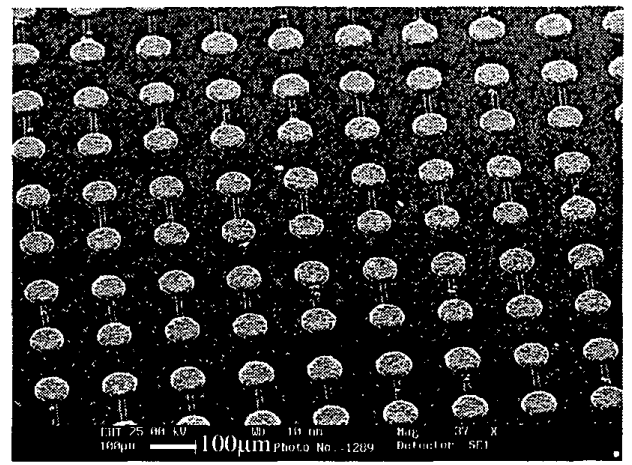

b)

Figure 5. Overall view of electroless nickel bumps a) wafer A, peripheral bondpads of $225 \mu \mathrm{m}$ and $300 \mu \mathrm{m}$ pitch with a 20 s double zincate pre-treatment b) wafer $B$, full array bondpads at $150 \mu \mathrm{m}$ pitch size with $10 \mathrm{~s}$ single zincate pretreatment.

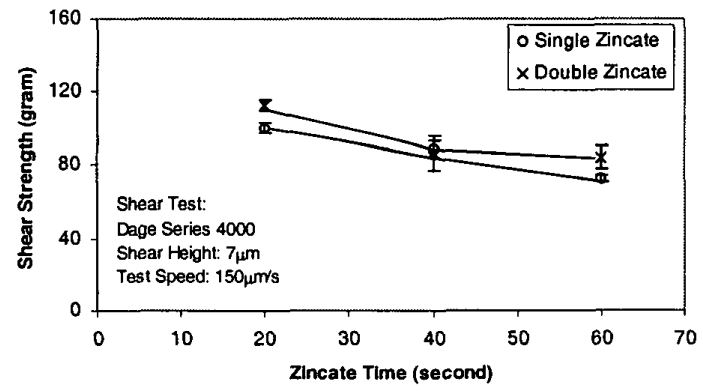

Figure 6. Shear test results for $225 \mu \mathrm{m}$ pitch bondpads on Wafer A

Good adhesion of the electroless nickel layer to the $\mathrm{Al}$ pad substrate is particularly important in order to achieve good reliability of the device during operation. In order to measure this, shear tests were performed on wafers that had been bumped with electroless nickel to a thickness of around $15 \mu \mathrm{m}$. Figure 6 shows the shear strengths obtained from Ni bumps on wafer $\mathrm{A}$, at a $7 \mu \mathrm{m}$ shear height, and $150 \mu \mathrm{m} / \mathrm{s}$ shear speed. In agreement with other studies, the $\mathrm{Ni} / \mathrm{Al}$ interfacial adhesion produced with a double zincate treatment is generally better than that with single zincate. It is easy to correlate this enhanced adhesion with the very thin, uniform $\mathrm{Zn}$ layer generated by the double zincate process. Many other factors such as the etched surface morphology, etc. will also influence the adhesion and will be discussed later. It was found that extending the zincate immersion time to 40 and 60 s was detrimental to the shear strength.

Surprisingly, as shown in figure 7 the shear strengths for $\mathrm{Ni}$ bumps on wafer $\mathrm{B}$ using $10 \mathrm{~s}$ zincate treatment (either single or double) were extremely good provided that a 10 s etch in a $5 \% \mathrm{NaOH}$ solution was carried out before $\mathrm{Ni}$ plating. However, the $\mathrm{Ni}$ coatings produced 
using a $20 \mathrm{~s}$ etch in $5 \% \mathrm{NaOH}$ solution had very poor interfacial adhesion, and the 20 s double zincate treatment gave even worse adhesion. For certain pre-treatments the shear strength of the bumps on wafer $B$ is even higher than those on wafer $\mathrm{A}$, despite the bondpads being smaller. This is surprising considering the less uniform nature of the zincate layer on wafer B compared to wafer $A$ which would be expected to reduce the adhesion of the nickel to the Al. However, one explanation for this effect may be the rougher morphology of the Al pad created by the zincate treatment, enabling more mechanical interlocking of the electroless nickel deposit to the bondpad thereby enhancing the shear strength. Bump pull tests could be used to try to eliminate this type of mechanical adhesion from the test results. For longer $\mathrm{NaOH}$ etch and zincate times, significantly lower shear strength values were obtained. This is thought to be the result of the more substantial etching of the $\mathrm{Al}$ pads created by these treatments leading to a considerable reduction in the thickness (and in some cases almost complete removal) of the $\mathrm{Al}$ pads.

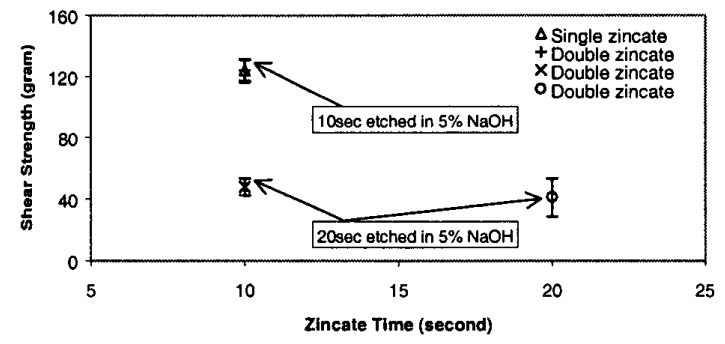

Figure 7. Shear test for $150 \mu \mathrm{m}$ pitch pads on wafer B

Figure 8 shows the fracture surfaces after shear testing of Ni bumps plated under different conditions. There are three main failure modes for the bumps during shear tests, one is brittle fracture from the $\mathrm{Ni} / \mathrm{Al}$ interface, which is the case for the Ni bumps produced with 10 s etching in $5 \%$ $\mathrm{NaOH}$ solution, as shown in figure 8 (a).

The second type of failure is a mixed fracture at the $\mathrm{Ni} / \mathrm{Al}$ interface and in the $\mathrm{Al}$ bondpad near the Si surface, as shown in figure 8(b). This was occasionally observed for 10s single and double zincate treated bumps after a $10 \mathrm{~s}$ etch in $5 \% \mathrm{NaOH}$ solution. The third failure mode was shearing through the $\mathrm{Al}$ pad near to the $\mathrm{Al} / \mathrm{Si}$ interface (figure 8 (c)), this was mostly found for double zincate treated bumps after a 20 s etch in $5 \% \mathrm{NaOH}$ solution.

Finally, electrical validation of the electroless $\mathrm{Ni}$ bumps was conducted using four point resistance measurements between pairs of interconnected pads. Table 2 summarises the results. For wafer $\mathrm{A}$, the average electrical resistance remained almost unchanged after $\mathrm{Ni}$ plating. However, for wafer B, for which the dimensions of the pads and tracks were much smaller than those on wafer $A$, the resistance increased slightly, for instance from $0.386 \Omega$ before bumping to $0.453 \Omega$ after nickel bumping of the $150 \mu \mathrm{m}$ pitch bondpads. These resistance increases may be attributed to the considerable reduction of the thickness of the $\mathrm{Al}$ pads during the UBM processing. As can be seen from Table 2, the resistance increase was seen after zincate processing but before $\mathrm{Ni}$ plating. The longer the pads were etched in $5 \% \mathrm{NaOH}$ solution, the greater the increase in electrical resistance. This further confirms that the thickness reduction of the $\mathrm{Al}$ pads caused a slight increase of resistance rather than the $\mathrm{Ni}$ coating and is in accord with the shear test results. It is clear that, the thickness of the $\mathrm{Al}$ pads for wafer $\mathrm{B}$ is critical, and care must be taken during processing to maintain it.

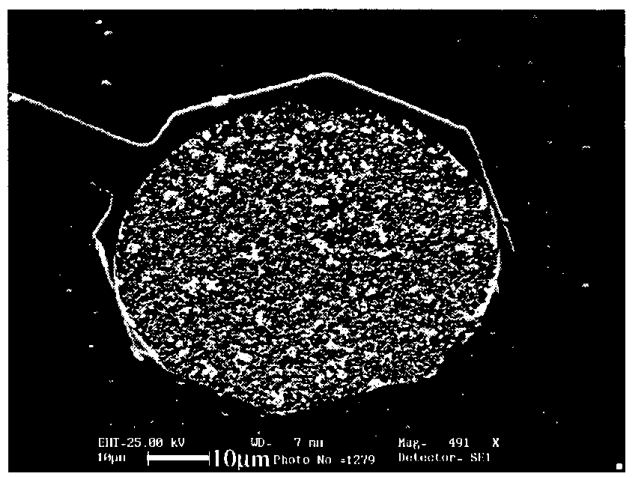

a)

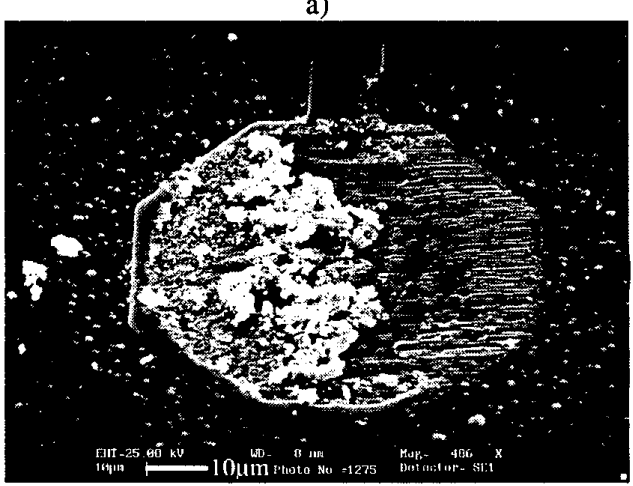

b)

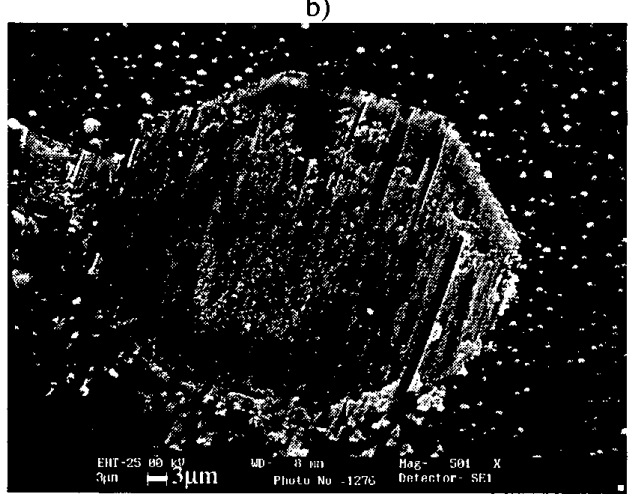

c)

Figure 8. SEM micrographs of the fracture surfaces of $\mathrm{Ni}$ bumps on wafer $\mathrm{B}$ after shear testing: a) and b) 10 s double and single zincate, $10 \mathrm{~s} \mathrm{NaOH}$ etch, c) 10 s double zincate, $20 \mathrm{~s} \mathrm{NaOH}$ etch. 
Table 2. Electrical resistances before and after zincate treatment or electroless nickel plating

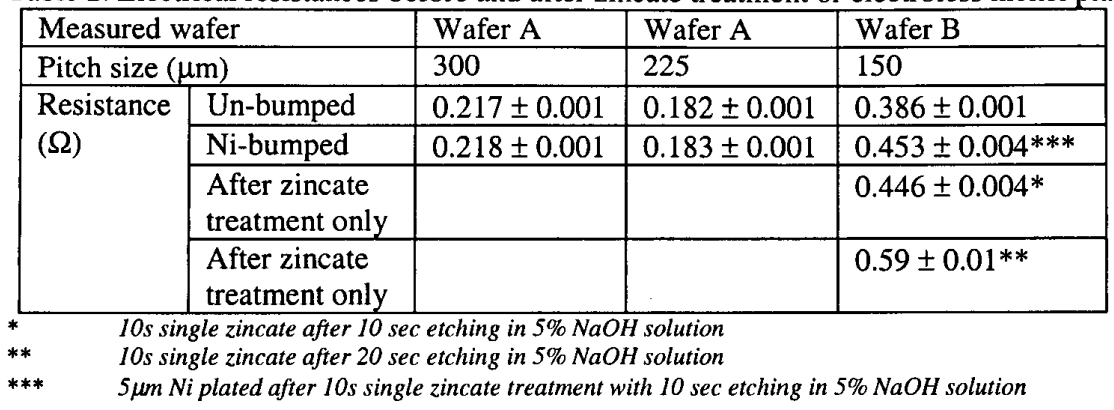

Table 3. Shear strengths (grams) measured for solder bumps from three selected die with solder paste printed and reflowed using different shear height

\begin{tabular}{|l|l|l|l|l|l|l|}
\hline \multirow{2}{*}{ Chip No. } & \multicolumn{7}{|c|}{ Shear Height (Microns) } \\
\cline { 2 - 7 } & $\mathbf{1 0}$ & $\mathbf{2 0}$ & $\mathbf{3 0}$ & $\mathbf{4 0}$ & $\mathbf{5 0}$ & $\mathbf{6 0}$ \\
\hline 1 & $44 \pm 3.5$ & $37 \pm 1.5$ & $32 \pm 2.7$ & $26 \pm 3.2$ & $18 \pm 2.4$ & $19 \pm 8.8$ \\
\hline 3 & $69 \pm 5.8$ & $36 \pm 2.4$ & $33 \pm 1.7$ & $25 \pm 1.6$ & & \\
\hline
\end{tabular}

\section{Stencil solder paste printing on the $U B M$}

Stencil solder paste printing followed by reflow was used to generate solder balls on the UBM of electroless nickel coating. Figure 9 shows typical bumps on wafer A which following printing and reflow, showed consistently well formed bumps and reasonable height. The UBM was an electroless $\mathrm{Ni}$ layer prepared with 20 s double zincate treatment.

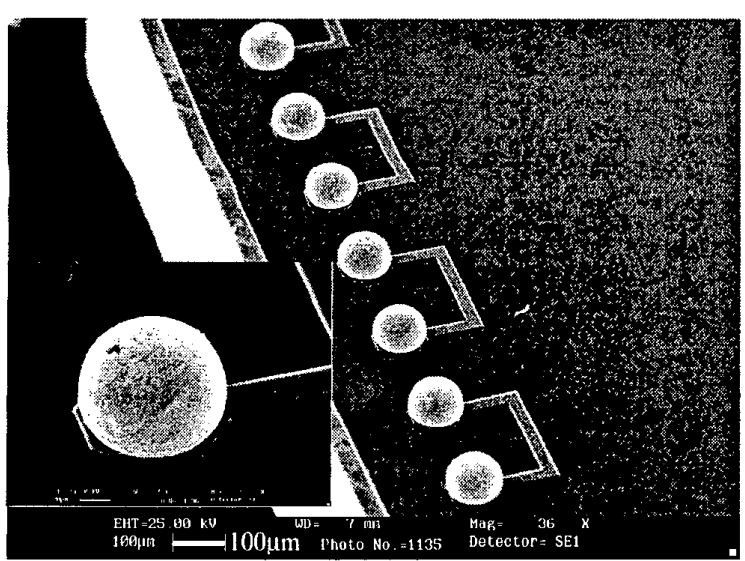

Figure 9. Stencil printed and reflowed solder bumps on UBM of $225 \mu \mathrm{m}$ pitch Al-Cu bondpads on wafer A.

Table 3 shows the results from shear testing of the solder bumps. The shear strengths presented are from three die selected at random from the wafer and use a range of shear heights. More than 20 measurements were made for each obtained mean value. Depending upon the shear height, shearing can take place through a different crosssectional area leading to different values of the shear strength. The solder balls have a height of approximately $80 \mu \mathrm{m}$ and the maximum section of sphere of the solder ball is at a height of 20 to $30 \mu \mathrm{m}$. The measured shear strengths at 20 and $30 \mu \mathrm{m}$ shear heights showed consistent and repeatable results. SEM examination of sheared samples indicated that the failure of sheared bumps took the form of plastic fracture through the bulk of the solder balls, confirming that the UBM had provided a reliable interlayer for solder processing.

\section{Conclusions}

The electroless nickel deposition technique has been investigated and used to generate an UBM interlayer for subsequent solder paste stencil printing in order to achieve a low cost fine pitch flip chip assembly process.

1. The initial structure and composition of the bond pads can affect the UBM process. The zincate film was finer-grained, thinner and more uniform on the smooth $\mathrm{Al}-\mathrm{Cu}(1 \%)$ alloy pads of wafer $\mathrm{A}$ than on the coarser microstructured pure $\mathrm{Al}$ pads of wafer B.

2. The double zincate produced finer, thinner and more uniform zincate layer than single zincate on wafer $\mathrm{A}$, because of the flattening effect of the removal of the first $\mathrm{Zn}$ layer with nitric acid and the considerably greater numbers of nucleation sites created. However this did not apply to wafer B.

3. The composition and thickness of the Al bondpad can lead to different dissolution rates in the $\mathrm{NaOH}$ and zincate solutions and preferential etching may occur at grain boundaries. This is particularly important for the pure $\mathrm{Al}$ bondpads on wafer $\mathrm{B}$, which are as thin as $1 \mu \mathrm{m}$ and could be damaged by the process.

4. A mushroom shaped bump was produced on both wafer $\mathrm{A}$ and $\mathrm{B}$, but the Ni bumps were more uniform in shape and surface finish on wafer $A$, because of the smoother, thinner and denser 
zincate layer formed on the pads before $\mathrm{Ni}$ plating.

5. Shear strength and electrical resistance measurements have validated the reliabilty of electroless nickel coatings on the bondpads of both wafer $\mathrm{A}$ and wafer $\mathrm{B}$. The solder bumps produced by solder paste printing and reflow on these UBM interlayers were confirmed to have a uniform and adequate bump height and good adhesion to the underlying pad.

\section{Acknowledgments}

The authors would like to thank the EPSRC for financial support under Grant No. GR/L61767. The technical support of Celestica UK, Mitel Semiconductor, Multicore Solders, DEK Printing Machines, Matra Bae, Intarsia Corporation, Salford University and Queen's University of Belfast is also gratefully acknowledged.

The authors would also like to acknowledge Mr. M. Hendriksen of Celestica Limited and Dr. T. Nguty of Salford University for their contribution to the preparation of solder bumped wafers through solder paste printing.

The technical support of Mr. J.T.W. Smith and Mr. P. Wileman is also greatly appreciated.

\section{References}

1. Kallmeyer, C., E. Jung, P. Kasulke, R. Azadeh, G. Azdasht, E. Zakel and H. Reichl, "A New Approach to Chip Size Package Using Meniscus Soldering and FPC-Bonding", IEEE Trans. CPMT, C, 21 (1998) 51.

2. Motulla, G., P. Kasulke, K. Heinricht, A. Ostmann, E. Zakel and H. Reichl, G. Aszdasht and J. Kloeser, "A Low Cost bumping Process for Flip Chip Technology Using Electroless Ni/Au Bumping and Solder Ball Placement", Advances in Electronic Packaging Conference 19-1 (1997) 57.

3. Liu, J., "Development of a Cost Effective and Flexible Bumping Method for Flip-chip Interconnections", Hybrid Circuits 29 (1992) 25

4. Wiegele, S., P. Thompson, R. Lee and E. Ramsland, "Reliability and Process Characterisation of Electroless Nickel-Gold / Solder Flip Chip Interconnect Technology", Proc. $48^{\text {th }}$ Electronic Components and Technology Conference (1998).

5. Tan, Q., C. Beddingfield, A. Mistry and V. Mathew, "Zincation Characterisation for Electroless $\mathrm{Ni} / \mathrm{Au}$ UBM of Solder Bumping Technology", Proc. IEEE / CPMT Int. Electronics Manufacturing Technology Symposium (1998) 34.

6. Lu, S.W., R.H. Uang, K.C. Chen, H.T. Hu, L.C. Kung and H.C. Huang, "Fine Pitch Low-Cost Bumping For Flip Chip Technology", Proc. $24^{\text {th }}$ IEMT Symposium, Austin, TX, October 1999, pp127.

7. Beddingfield, C., Q. Tan and A. Mistry, "Evaluation of Eutectic Solder Bump Interconnect Technology", Proc. $24^{\text {th }}$ IEMT Symposium, Austin, TX, October 1999, pp131.

8. Thorsten, T., T. Oppert, E. Zakel, E. Klusmann, H. Meyer, R. Schulz, J. Schulze. "A Low Cost Electroless Process for Wafer Level CSP and RDL",
Proc. IEMT Europe 2000, Munich, Germany, April 2000.

9. Monteiro, F.J., M.A. Barbosa, D.H. Ross and D.R. Gabe, "Pretreatments to Improve the Adhesion of Electrodeposits on Aluminium", Surf. Interface Anal., 17(1991)519.

10. Pearson, T., and S.J. Wake, "Improvements in the Pretreatment of Aluminium as a Substrate for electrodeposition", Trans. Inst. Met. Fin., 75(1997)93.

11. Zakel, E., and H. Reichl in "Flip Chip Technology", Edited by J.Lau, 1995.

12. Han, J.I., S.J. Hong, "Ni Electroless Plating Process for Solder Bump Chip on Glass Technology", Jpn. J. Appl. Phys., 36(1997)2091.

13. Robertson, S.G., I.M. Ritchie, "The Role of Iron(III) and Tartrate in the Zincate Immersion Process for Plating Aluminium", J. Appl. Electrochem. 27 (1997) 799.

14. Lee, C.Y., K.L. Lin, "Preparation of Solder Bumps Incorporating Electroless Nickel-Boron Deposit and Investigation on the Interfacial Interaction Behaviour and Wetting Kinetics", J. Mat. Sci: Mat. In Electronics 8(1997) 377 